\title{
Etnografías sin final feliz. Sobre las condiciones de posibilidad del trabajo de campo urbano en contextos globalizados
}

\author{
FRANCISCO CRUCES \\ Dpto. de Psicología Social y Antropología \\ Universidad de Salamanca
}

\section{RESUMEN}

¿Qué justificación epistemológica cabe dar hoy a la actividad etnográfica en contextos donde el flujo de personas, saberes y significados erosiona todo sentido cerrado, autocontenido, de cultura? ¿Qué lugar seguir concediendo a los conceptos clave que apuntalaban nuestras rutinas de investigación, a palabras tales como "lugar", "Comunidad" O "culturaw? Partiendo de la premisa de una transformación radical en las condiciones contextuales en que hemos de desplegar nuestra práctica profesional, el presente artículo trata de caracterizarlas, centrándose en (1) el problema del holismo, (2) la naturaleza de la cronotopía contemporánea y (3) la inconmensurabilidad de saberes. Lejos de un abandono de la etnografía como método, este análisis trata de argumentar el potencial heurístico de la interpretación etnográfica para reconstruir las conexiones inesperadas entre realidades culturales distantes en un mundo unificado espacial y temporalmente.

Palabras clave: Antropología urbana, Etnografía, Trabajo de campo, Globalización.

\section{SUMMARY}

What is the epistemological justification for current ethnography, at a time when the flux of persons, knowledge and meanings erodes any closed, self-contained sense of culture? What will be the theoretical role played by key concepts such as "culture", "Community" and "place," until now used to lay the groundwork for our routines of research? On the basis of this deep transformation underway of the contextual conditions for ethnography, this paper explores some of them, focusing on three problems: (1) holism, (2) the nature of contemporary chronotopy and (3) the incommensurability of knowledge. Far from an abandonment of ethnography as a method, the author argues for the heuristic potential of ethnographic interpretation for reconstructing the unexpected connections among distant cultural realities in a temporally and spatially single world.

Key words: Urban Anthropology, Ethnography, Fieldwork, Globalization.

RDTP, LVIII, 2 (2003): 161-178 


\section{EL FIN DE LAS RUTINAS ETNOGRÁFICAS}

El trabajo de campo como método ha sido caracterizado en las últimas décadas, ante todo, como una forma de escritura. Haciendo énfasis en la construcción autorial del texto, la caracterización de la posición del observador, la visibilidad o transparencia de su subjetividad, la relación entre el tiempo del relato y el tiempo nativo en el que viven los informantes, distintos críticos nos han hecho considerar el carácter de la etnografía como representación del Otro: una representación a menudo denunciada como parcial, deformadora, interesada, o congelada; o incluso como cosificadora, sesgada, autoritaria y dominadora. Pero en cualquier caso, siempre construída (ver Fabian 1983; Geertz 1987; Clifford y Marcus 1995).

Si bien es cierto que la etnografía es inevitablemente escritura (o puesta en escena, su equivalente para el caso de la antropología visual y la etnomusicología), no siempre se insiste lo bastante en el hecho de que a esas construcciones se llega por un proceso que no es exclusivamente narrativo. Implica, sobre todo, un tiempo largo de contacto personal, de pequeñas negociaciones sobre el terreno, de aprendizaje de nuevas formas culturales, de reordenación de la propia intimidad y de la vida cotidiana, de relación con lenguajes y modos de expresión incomprensibles o por lo menos desconocidos, de asimilación de códigos de conducta ajenos, etc. Desde este punto de vista, el trabajo de campo no es sólo narrativa: es también experiencia. Y aún mejor lo caracterizaríamos, como hacen Velasco y Díaz de Rada (1999: 18), en términos de proceso: un proceso de incesantes idas y venidas desde la experiencia vivida al papel escrito, de la observación a la entrevista, de la entrevista al diario, del diario al texto etnográfico, y vuelta a empezar. Así se dibuja un modus operandi cuyos rasgos distintivos frente a otros métodos de las ciencias sociales podemos identificar por a) la instrumentalización de las relaciones sociales sobre el terreno (una involucración de las personas que incluye la del propio etnógrafo como medio de construcción de conocimiento), b) la importancia del punto de vista local (la etnografía es siempre un modo de conocimiento situado), c) la sensibilidad al contexto y d) la imbricación simultánea de diferentes niveles de realidad. El resultado es que las representaciones del Otro que resultan de este dispositivo se mantienen en una característica tensión entre proximidad y distancia, empatía y extrañamiento, observación y participación; una tensión ausente en otras formas de narrativa científica, en las que la imbricación entre teoría y datos no se halla tan íntimamente ligada al locus de la persona del observador (Velasco y Díaz de Rada 1999; Peacock 1993). Lo original de la invención malinowskiana radicó precisamente en reconfigurar radicalmente la 
división del trabajo científico entre etnógrafo de campo y antropólogo de sillón, haciendo de la tarea etnográfica la de un "ojo que piensa".

Tradicionalmente, este modus operandi complejo se ha volcado en lo que yo llamaría "narrativas del embrollo con final feliz". El embrollo define la situación de partida de la etnografía: una situación comprometida, de desplazamiento, desubicación o franco merodeo, en la que el antropólogo se ha colocado voluntariamente y que en seguida desembocará en frustración, malentendidos y desencuentros con los nativos. Es la fase de entrada en el campo, en la cual, tras haber resuelto las principales cuestiones materiales de una estancia, el etnógrafo hace preguntas sin ser respondido, comete involuntarias descortesías, busca crearse una red de relaciones o escapar a algunas otras, se pregunta qué hace allí, se frustra y encierra a leer novelas, contrae enfermedades tropicales, etc. Pero, sobre todo, es el momento en que el recién llegado afronta la otra cultura de un solo golpe, experimentándola como algo inabordable - galimatías, rompecabezas, jeroglífico, laberinto o embrollo semiótico-. Un ejemplo bien conocido es el de Evans-Pritchard cuando, al comienzo de su monografía sobre los Nuer, afirma estar volviéndose "nuerótico" ante la habilidad de éstos para eludir sus preguntas (1977: 25). O la frustración de Malinowski en su primer intento de "hacer tecnologia" entre los trobriandeses (1993: 135). O aquel otro de J. Peacock, en el que cuenta un sueño en el que, por tratar de dar limosna a un mendigo javanés, se acaba viendo obligado a entrar con él a un banco para comprarle cheques de American Express (Peacock 1993: 171). Ejemplos no faltan: la especialidad de sobremesa de nuestra profesión consiste en intercambiar anécdotas sobre los enredos, aprietos y malentendidos vividos en el campo.

No obstante, lo que hace de la narrativa del embrollo algo más que un mero anecdotario es su virtualidad para situar un problema dentro de una retórica específica. Por así decirlo, el embrollo es vivido como situación práctica, pero se inserta en el relato como testimonio tangible de la diferencia cultural y, a partir de ahí, como un pretexto para el despliegue conceptual que va a organizar la monografía subsiguiente. En ese sentido, no se trata sólo de trucos de autor, sino de una retórica de la iluminación.

El rasgo de esa retórica sobre el que deseo llamar la atención es su final feliz. A lo largo de la monografía clásica el embrollo va quedando atrás, como ejemplo de una fase superada del trabajo científico. Al final del texto se cerrará el arco explicativo tendido por aquel problema inicial: de algún modo, los nativos han sido entendidos, el antropólogo ha conseguido integrarse en el grupo, los misterios de la cultura han sido parcialmente elucidados. Algunos autores, como Marvin Harris, construyen sus textos como auténticos enigmas susceptibles de resolución, a la manera de una intriga de novela negra. En otras narrativas etnográficas menos esquemáticas percibimos el género de 
la monografía antropológica como una propuesta de traducción intercultural: una mediación exitosa por la cual el mundo de sentido de los estudiados se abre a la comprensión del antropólogo y sus lectores (sobre este concepto de antropología como traducción, cf. Asad 1991; Tambiah 1990: 111 y ss.). Tomando prestada la terminología de Peirce, podríamos decir que el carácter de esta operación semiótica es abductivo. No se trata propiamente de una inducción empírica ni tampoco de una falsación hipotético-deductiva, sino una operación en la que el antropólogo interpreta, como mediador entre dos lenguajes, la relación de semejanza postulable entre ambos, estableciendo puentes de sentido mediante parecidos de familia entre fenómenos y regiones de la experiencia cultural que permitan acercarlos, hacerlos mutuamente inteligibles. En la escritura etnográfica se produce, por tanto, una especie de superposición entre el trabajo de campo como experiencia y como relato. En la medida en que, a través del discurso científico, el lector participa vicariamente de la experiencia de resocialización reflexiva del antropólogo, puede asistir a la apertura de ese mundo, inicialmente cerrado y opaco, de la cultura observada.

Ciertamente, a estas alturas no faltan ironías sobre esta narrativa maestra. La más divertida seguramente es la de Nigel Barley sobre su trabajo entre los Dowayo de Camerún en El antropólogo inocente, diario de viaje donde el autor da cuenta con sorna de los engaños de los informantes, las penurias de la estancia y los dos dientes que un dentista camerunés le arrancó sin avisar. También cabría recordar un breve artículo, muy anterior, de L. Bohannan, "Shakespeare en la selva", una deliciosa fábula en la que la autora trata infructuosamente de transmitir el argumento de Hamlet a los Tiv de África Occidental, y que funciona como una suerte de metáfora de los intentos vanos de nativos y antropólogos por hacerse entender mutuamente desde las categorías propias (Barley 1989; Bohannan 1993. Para una revisión del discurso etnográfico como alegoría, cf. Clifford y Marcus 1991; Cruces 1994. Sobre la impostura etnográfica ver Zulaika 1994).

Más allá de estas ironías y de las deconstrucciones literales a las que recientemente ha sido sometido nuestro procedimiento de investigación, su principal fuente de erosión se halla, en realidad, en las propias transformaciones en curso de la cultura contemporánea, las cuales suponen en sí mismas un desafío a la imaginación teórico-metodológica de las nuevas generaciones de antropólogos. Desde lo que de distintos modos se etiquetó, primero, como crisis de objeto de la antropología (en los años sesenta), luego como crisis de representación o de autoría (en los ochenta), los relatos de etnografía con final feliz han ido resultando no sólo cada vez más escasos, sino también más inverosímiles. En la medida en que este modelo de narrativa constituía, en realidad, un paradigma propio de la época de la antropología colonial, 
los procesos subsiguientes de descolonización, urbanización, modernización y globalización han minado sus condiciones de posibilidad. Lo que no tenemos, sin embargo, es una definición suficientemente clara de las nuevas condiciones bajo las cuales se desarrolla actualmente el trabajo etnográfico, ni mucho menos de los aspectos en los que afectan a nuestro modus operandi y de las narrativas adecuadas a tales condiciones, las cuales se encuentran en buena medida por explorar.

En otros términos, de lo que se trata es del ajuste entre los relatos que nos guían y las circunstancias en que desplegamos nuestra práctica profesional. Yo pertenezco a una generación que ha aprendido la antropología en los textos de Evans-Pritchard, Malinowski, Leach, Lévi-Strauss, Harris y Geertz. Sin embargo, a la hora de hacer etnografia hemos tenido que descubrir, junto con la riqueza de hallazgos que proporciona esta tradición, la inmensa distancia entre las realidades que estudiamos y esas lecturas donde están depositados los modelos canónicos de la antropología ${ }^{1}$. Por ello hemos tenido que abrirle puertas de escape al canon (podríamos llamarlas, parafraseando a Appadurai, field-scapes), y también trazar atajos que lo conectaran con la realidad etnografiada. Expertos por fuerza en el pastiche metodológico (en una era de collage cultural) y en el nomadismo disciplinar (en una era de transfuguismo epistemológico), nuestras etnografías son testimonio de nuevas tensiones a añadir a las ya clásicas: las que se derivan, por ejemplo, de la indistinción entre nuestro saber como expertos y el de nuestros informantes; o de la carencia de un rol definido desde el cual relacionarnos con éstos, recogiendo el testimonio de una tradición; o de la imposibilidad misma de acotar cómodamente los límites culturales de un grupo humano como objeto de estudio. Nuestras etnografías, cuando son honestas, carecen de final feliz, si no es por un violento efecto de clausura narrativa que ninguno de nosotros puede íntimamente tomar en serio.

Dada la estrecha ligazón entre teoría y procedimiento en etnografía, es comprensible el impacto que tales condiciones poseen sobre ambos niveles. Esbozar muy modesta y sucintamente algunos aspectos de ese impacto será el objeto de este ensayo. En lo que sigue destacaré tres grandes apartados en los que a mi juicio cabe apreciar modificaciones importantes de las rutinas heredadas en el trabajo etnográfico: 1) el holismo o la construcción de

${ }^{1}$ En este problema, nuestros maestros difícilmente podían ayudarnos, sencillamente porque se encontraban en el mismo brete. Las etnografías al uso en España, entre el localismo y el cosmopolitismo, han tratado de hacer explícitas las deficiencias de los modelos importados de la antropología social inglesa y la antropología cultural norteamericana, sin por ello distanciarse de modo sustancial, en la práctica, de sus rutinas etnográficas. 
totalidades, 2) el carácter de la cronotopía en la modernidad avanzada, 3) la inconmensurabilidad de los saberes del antropólogo y sus informantes.

\section{HOLISMO}

La etnografía no puede renunciar a la pretensión de totalidad sin traicionarse. Ciertamente, la imagen de la totalidad cultural, a la que obliga el precepto holista del trabajo de campo, ha ido adoptando diferentes versiones en distintos paradigmas teóricos: el hecho social total maussiano, el pattern de cultura y personalidad, las nociones de sistema e institución en los diversos funcionalismos, el patrón universal de la ecología cultural - todos ellos representan modelos de totalidad-. El gran hallazgo del trabajo de campo malinowskiano, que supuso una superación innegable de todas las formas anteriores de etnografía, consistió precisamente en sustituir la visión fragmentada y estratigráfica que de la vida primitiva proyectaban los evolucionistas por la sistematicidad en el tratamiento del contexto como un todo complejo e integrado, del que no se pueden desgajar las piezas sin deformarlas. La verdad etnográfica es siempre relacional. Desde entonces, la antropología es una teoría de la imbricación sociocultural.

El concepto clave en las justificaciones metodológicas del holismo es, qué duda cabe, el de cultura. En la tradición de la disciplina, las rutinas heredadas tienden a la reproducción de un concepto insular de la misma, cuya relación con nuestras unidades de observación toma la forma de un sistema de cajas chinas. Por ejemplo, según el modelo malinowskiano, Los Argonautas se propone como una etnografía del Kula, aunque principalmente recoge información de uno solo de los archipiélagos implicados - las Trobriand-, y la masa de sus observaciones procede de una sola de sus islas - Kiriwina- y todavía más concretamente de un poblado - Omarakana- (Malinowski 1992). Aclaro que no estoy trayendo a colación el gastado argumento sociológico de la representatividad estadística de las unidades de observación, sino más bien quiero llamar la atención sobre la naturaleza de esa globalidad que llamamos "cultura" y del vínculo que mantiene con los datos particulares producidos muy localmente por el etnógrafo. Algunos de esos supuestos se hallan expresados de forma paradigmática en la noción de Redfield de la comunidad folk: un contexto tradicional, poco cambiante, homogéneo, aislado, sin escritura, comunitario, distintivo, de pequeño tamaño, autosuficiente -el tipo ideal que él situaba al extremo del continuum folk-urbano- (Redfield 1960).

Si bien esa pequeña comunidad, versión antropológica de la Gemmeinschaft de Tönnies, ha constituido históricamente un modelo a escala para pensar el concepto de cultura, irónicamente asistimos hoy a la difusión y 
generalización de este concepto orgánico y totalizante justo en el momento en que la antropología profesional lo abandona y en el que tales formas de organización humana tienden aceleradamente a reconvertirse, a hibridarse o al menos a dialogar con los procesos de la interconexión global. Ahora todos los empresarios hablan de la "cultura" de sus empresas, los políticos quieren "recuperar y defender los valores de la cultura", los sindicatos hablan de "cultura obrera", los obispos de "cultura del perdón" y los periodistas de "cultura del pelotazon. Las diversas culturas proliferan: la europea, la madrileña, la latina, la mediterránea, la andaluza, la surandaluza, la rural, la ciudadana, la alimentaria, la del cuerpo, la del ocio, etc. etc.

En una especie de movimiento inverso a esta popularización, la antropología de las últimas décadas ha ido minando el concepto, al poner en claro algunas de sus fisuras como instrumento para construir una imagen adecuada de las totalidades que estudiamos:

1) Su tendencia a pasar por alto las diferencias internas, la pluralidad, diversidad y heterogeneidad constitutivas de todos los grupos humanos, modernos o tradicionales; algo que trató de ser superado por Wallace con la redefinición de cultura como "organización de la diversidad" (Wallace 1972).

2) La creciente borrosidad de límites, adjudicable tanto a los conjuntos de formas y significados culturales como a los mismos grupos a los que teóricamente se adscriben tales formas; lo cual conduce a alternativas en la acotación del universo de estudio, como por ejemplo las de campo cultural (típicamente sociológica) o la de ecúmene, acuñada por Kroeber en 1945 para aludir a la interconexión del mundo, el "entramado de hechos y productos significativos" para el historiador y el antropólogo (Hannerz 1998: 21). O las propuestas de autores como Marcus (1995) o Appadurai (1986) en el sentido de seguir mediante la etnografía la circulación y el flujo de las personas, los objetos, los saberes, las metáforas, los discursos, en lugar de su acotación territorializada. En esta medida, podríamos hablar de un creciente desdibujamiento de los objetos tradicionales de estudio, con un énfasis cada vez menor en los límites de los objetos/sujetos socioculturales y cada vez mayor en sus intersecciones, cruces y trayectorias.

3) La recuperación del papel del agente (individual y colectivo) en la constitución de la cultura, de la cual los seres humanos no son vehículos pasivos. La insistencia de las diversas antropologías de la performance en la importancia situacionista del aqui-y-abora de los actores en la producción de sentido sociocultural, así como las nociones sociológicas de habitat (Bauman 1992) y agencia (Giddens 1994) se dirigen a la recuperación del sujeto frente a las epistemologías mecanicistas y causalistas, en un mundo de ofertas difu- 
sas y elecciones libres donde nos encontramos de algún modo "forzados a optar", esto es, a construir nuestro propio entorno.

4) El legitimismo autorizador y a menudo autoritario subyacente en los usos oficiales, mediáticos y también académicos de "la cultura" como mínimo denominador común de las poblaciones, tendente a objetivar los procesos culturales, cosificar las tradiciones, normalizar las diferencias y absorberlas en un modelo en mosaico de la diversidad social. Es este concepto reificado de la cultura -no como proceso vivido, sino como puro catálogo de identificaciones institucionalizadas- el que llevó recientemente a algunos autores a escribir "contra la cultura" (Abu-Lughod 1991) y a oponer a tales usos oficiales del concepto otros usos "demóticos", basados en la experiencia cotidiana de los sujetos (Baumann 1996).

La etnografía no puede elegir ser o no holista: será holista o no será nada. Sin embargo, las transformaciones mencionadas nos obligan a imaginar nuevos modos de construir totalidades a partir de los fragmentos, el flujo y la mezcla. La hibridación artística, el viaje, el montaje cinematográfico, el collage plástico, el diálogo literario, la sintonía musical y la escena teatral son algunos de los modelos de composición etnográfica que inspiran modos recientes de hacer etnografía, estrategias de totalización alternativas a los supuestos clásicos de la "cultura", la "sociedad" y la "comunidad". Con ello no desterramos de nuestro horizonte tales conceptos, pero tratamos de escapar a sus asunciones más ingenuas y peligrosas, convirtiéndolos —usando términos de Goody - en "mojones de orientación" del trabajo empírico (1992: 11 y 29).

Según Marcus, en un mundo de interconexiones globales, la etnografía ha de encontrar su sitio entre los discursos macro de la integración, fundamentalmente económicos y sociológicos, y los discursos micro de la fragmentación, fundamentalmente culturales y estéticos. Esa posición intermedia no debería de consistir en lo que a menudo hacemos al componer la etnografía uniendo observación local más teoría global. Consistiría, más bien, en renunciar a una imposible visión total, desarrollando un conocimiento estratégicamente situado en las fracturas, los márgenes, las interconexiones entre mundos que se tocan sin saberlo. En esa medida, nuestro método despliega su potencialidad como instrumento heurístico, descubriendo conexiones insospechadas entre fenómenos distantes y cuestionando conexiones dadas por supuestas. En este mundo culturalmente dislocado, tal vez la visión de la totalidad no pueda ser finalmente sino un producto ideológico (en el sentido marxista) y todo conocimiento haya de ser necesariamente situado.

Podemos entender la etnografía como una suerte de instantánea. No un dictamen definitivo sobre la causa o el sentido de los procesos culturales, sino una búsqueda de sentido. De ese modo realizamos, en realidad, un 
camino de vuelta antidisciplinar que nos acerca a la experiencia social de nuestros sujetos. Pues, lo mismo que el etnógrafo urbano, ellos están también abocados a tratar de orientarse en la ciudad inabarcable (García Canclini, Castellanos y Rosas 1996: 29, 107), a interaccionar con las instituciones modernas mediante atajos y tanteos (Velasco et al. en preparación), a casar conflictivamente las partes inconciliables o irreductibles de su herencia cultural (Baumann 1996), a hacer compatible el hecho de pertenecer a varios lugares al mismo tiempo (García Canclini 1999).

\section{CRONOTOPÍA TARDOMODERNA}

Un segundo problema metodológico conectado con el anterior se refiere a la pérdida de credibilidad de las coordenadas de tiempo y espacio en el relato etnográfico clásico.

Hacer trabajo de campo conlleva indefectiblemente una especie de ejercicio de topologización y sincronización de la cultura. En el esfuerzo por ajustar sus desplazamientos a un territorio abarcable y por sintonizar sus actividades con un ritmo de vida extraño -0 , por ponerlo a la inversa, en sus esfuerzos por mapear los lugares y abstraer el esqueleto temporal de las acciones nativas - todo etnógrafo enfrenta un problema central: el del encaje entre las coordenadas (representadas) de su escritura etnográfica y las coordenadas (vividas) del campo; entre la construcción abstracta y panóptica de un mapa y un calendario y la constitución, en realidad difusa, de la vida local.

Sus esfuerzos desembocan en lo que podríamos llamar, siguiendo a Bajtin, un cronotopo. Tomando la expresión bajtiniana, toda narrativa presenta un cronotopo particular, en el sentido de una puesta en relación entre, por una parte, los ejes de espacio y tiempo del narrador, en donde el relato tiene lugar, y por otra los de lo narrado, en donde se sitúan los personajes de la historia. El cronotopo es, en términos de Bajtin, ala conexión intrínseca de relaciones temporales y espaciales que se expresa de forma artística en la obra literaria" (1981: 84).

El cronotopo clásico de la etnografía, derivado de la práctica de campo en condiciones coloniales, privilegiaba la imagen de una heterogeneidad radical entre el espacio-tiempo de los nativos y el del narrador, que no se tocaban más que por la mediación puramente conceptual, intelectual, de este último. El modelo de espacio era, como hemos sugerido, el de la isla: un espacio culturalmente homogéneo y holísticamente abarcable, bien demarcado, apropiado por un grupo humano netamente definido, integrado simbólicamente y discontinuo con respecto a cualquier otra isla adyacente. A esta metáfora insular le corresponde también un tiempo propio: un ciclo. Es de- 
cir, un dispositivo de medida del tiempo autónomo, dotado de su propio alfa y omega, de unidades de duración distintivas, de un ritmo de sucesiones diferenciado y de una orientación del conjunto hacia eventos y conmemoraciones clave. El ciclo recorta un tiempo aparte, cerrado sobre sí mismo, eternamente renovado, que habla de la autonomía de una comunidad humana sobre los asuntos que le conciernen. Un tiempo inconmensurable con respecto al del observador, que el relato en un presente congelado, sin anticipaciones ni duración (lo que técnicamente denominamos "presente etnográfico"), tiende a poner en primer plano. Las "sociedades sin historia" de la etnografía clásica tienden a parecer, por ello, también sociedades sin futuro.

No quiero dar a entender que estas coordenadas resulten de una convención puramente arbitraria del relato. A mi juicio, están inscritas en la realidad misma. Pues es precisamente mediante la constitución de un territorio demarcado y un tiempo propio - es decir, de un lugar- como la gente puede llegar a identificarse y ser identificada como diferente. En esa medi$\mathrm{da}$, la insularidad se manifiesta a ojos de los agentes como una verdad incuestionable que afirma su identidad.

Sin embargo, este régimen espacial y temporal de las culturas tradicionales ha sido desbordado en la modernidad avanzada por procesos de transformación que producen un desfase creciente: entre, por un lado, las prácticas locales y las coordinaciones presenciales de la acción y, por otro, los ejes dominantes de referencia que les otorgan valor y legitimidad en el espacio-tiempo global. (Pensemos, por ejemplo, en la fiesta comunitaria, local y tradicional, que hoy se expresa mediante la irrupción de todo tipo de formas simbólicas ajenas, en principio, al lugar festivo: bailarinas de samba en pueblos extremeños, músicos de gaita y tamboril en festivales bogotanos, etc.). Lo más llamativo del proceso globalizador reside en que incluso aquellas esferas de integración supralocal —como lo comarcal, lo nacional o lo clasista- que alguna vez se dieron como sólidas y definitivas están siendo, a su vez, desgastadas o rebasadas por rápidos procesos de articulación (Cruces 1997).

No pienso que la alternativa a esta forma de cronotopía sea lo que en otro lugar he denominado "el modelo abstractivo" del espacio-tiempo - la noción de una universalización abstracta del tiempo y una compresión del espacio ligadas a los procesos de desarrollo del capitalismo-. Pese a las tendencias crecientes al control, la estandarización y la medida del tiempo social, no creo que exista lo que Giddens formula como "tiempo vacío", ni que la desterritorialización y dislocación de la cultura hagan del lugar "una fantasmagoría" (cf. Giddens 1994: 133). En realidad, cabe llamar la atención sobre el carácter esencialmente negativo de los conceptos asociados a este modelo de racionalización y abstracción: nociones como "no-lugar" (Augé 1998), "desanclaje" (Giddens 1994) o "desterritorialización" (Martín Barbero 1987) nos 
hablan más de lo que el tiempo y el espacio de las localidades ya no son que de aquello en lo que de hecho se están convirtiendo.

Personalmente, me convencen algunas razones que salvaguardan el peso constitutivo de lo local, en el sentido de lo presencial (el cuerpo, las relaciones cara a cara y las vinculaciones personales) en la cultura global. El primer dato es que los ricos del mundo siguen viviendo juntos, en proximidad física. Pese a la ideología de la abolición del espacio y sus ataduras, para hacer negocios los grandes de la tierra siguen necesitando verse y tocarse -cenar juntos, jugar al tenis, contarse chistes de políticos y banqueros-. Lo hacen en lugares como Manhattan, la City de Londres, Tokio, París, Mallorca. En segundo lugar, solemos asociar la idea de cultura global a los medios de comunicación, y la local a las relaciones presenciales, pero hoy día una de las mayores fuentes de circulación de cultura global (de formas y significados deslocalizados) pasa por vínculos y redes personales de gentes que van y vienen de su localidad (Hannerz 1998). Hay quien ha denominado esto "la otra globalización”, una globalización por abajo. En tercer lugar, esas relaciones continúan teniendo, por su densidad afectiva y semántica, la importancia que siempre tuvieron para la constitución de la identidad personal: construyen las rutinas de la vida cotidiana, se desarrollan en relaciones inclusivas, cara a cara y de larga duración, se asocian a experiencias tempranas y, sobre todo, son de orden sensual, corporal. Puede que existan fiestas en internet, pero nunca serán lo mismo. En resumen, se puede argumentar, con K. Hastrup, que "todos somos nativos de algún mundo", en el sentido de que la práctica social incluye, como la enunciación, una autorreferencia implícita al aquí-ahora de los agentes (Hastrup 1994: 175). Un tiempo y un espacio plenamente vacíos son tan imposibles como un habla libre de acento o un conocimiento libre de punto de vista.

Un modelo cronotópico habrá de partir por tanto de una noción situacional, dialógica y enunciativa de la localidad, preguntándose por los esquemas prácticos y discursivos que permiten a los agentes conectarse y desconectarse de distintos modos con las coordenadas del contexto inmediato y de la sociedad como un todo. Un modelo de este tipo se centra en las tácticas, a menudo improvisadas y oportunistas, que permiten a individuos y grupos posicionarse en el espacio abstracto y temporalizar el tiempo universal (Munn 1992). Tales operaciones se corresponden con aspectos del proceso de reanclaje aún insuficientemente trabajados desde la etnografía. En esta época marcada por la convivencia entre lo familiar y lo extraño, los actores ponen en juego saltos y atajos para situarse entre niveles de realidad a menudo inconmensurables, fragmentados o hibridos.

Así, el nuevo espacio-tiempo de la etnografía no aparece como una superficie plana, homogénea, dada de una vez por todas, sino que se fragua y 
se reformula constantemente mediante procesos de poder, negociación y conflicto. Implica la formación de nuevos "mapas del mundo" como formas globalizadas de geopoder (Agnew 1998; Guaderrama 1999), así como también las maneras localizadas de adaptarse a ellos. Consecuentemente, el proceso no puede ser relatado desde la perspectiva ideal de un observador omnisciente, situado en el centro del espacio-tiempo global, sino más bien desde sus márgenes, persiguiendo trabajosamente las sinuosidades del punto de vista de actores concretos. La propuesta programática de Marcus de una etnografía multisituada (1995) apunta en esa dirección.

\section{INCONMENSURABILIDAD DE SABERES}

Las etnografías clásicas pueden entenderse como formas de mediación intercultural: traducciones exitosas entre mundos inconmensurables, donde una comparación término a término conduciría a producir errores categoriales (Leach 1971; Turner 1984; Asad 1991; Tambiah 1990). La puesta en contexto de las creencias y las prácticas permite hacer ver su sistematicidad, la congruencia interna que marca todo sistema simbólico, y con ello su inteligibilidad desde el sistema de referencia propio. Vemos así los arriesgados viajes del Kula como una ambición emocionante, el recurso Zande a la explicación por la brujería como algo próximo a nuestro concepto de azar, las circuncisiones Ndembu como rito de paso y entrada en la edad adulta. En este juego translaticio, el antropólogo opera con dos tipos de relaciones conceptuales: las internas, explicando cada término del mundo nativo en función de los otros, y las externas, relacionando términos o grupos de términos del lenguaje observacional con los de la teoría antropológica e, implícitamente, con los de la cultura urbana de Occidente.

Podemos preguntarnos qué queda de este elegante modus operandi en nuestros contextos etnográficos habituales. Aparecen tres tipos de problemas. En primer lugar, la imposibilidad de acotar un contexto. ¿Cuánto contexto es "el contexto"? Es decir, ¿qué tipo de datos está justificado considerar necesarios para hacer viable la traducibilidad? Este es un problema viejo, ya planteado en los debates de la antropología social inglesa (Turner 1984; Asad 1991; Tambiah 1990; Cruces 1994). La conclusión del debate, si es que la hubo, parece haber sido que no existe manera de definir a priori qué será considerado "contexto etnográfico" sino por el fiat autorial del antropólogo. No obstante, el problema de los límites del contexto se hace mucho más acuciante en la sociedad contemporánea: no sólo por su apertura espaciotemporal a formas culturales venidas de todo tiempo y lugar, sino sobre todo por la intervención masiva en la vida cotidiana de lo que Giddens denomina 
sistemas expertos (es decir, formas de saber desancladas y basadas en la división social del trabajo). Los saberes que queremos traducir están hoy irremisiblemente mediados por las formas racionalizadas de la ciencia, la tecnología, la escuela, los medios de comunicación, el mercado y demás instituciones de la modernidad.

En segundo lugar, el ejercicio de una antropología en casa (sea cual sea el sentido que queramos atribuir al término "estar en casa") imposibilita separar analíticamente ambos lenguajes (o, mejor dicho, los tres lenguajes: el lenguaje objeto del nativo, el lenguaje propio del antropólogo y el tercer lenguaje de la teoría antropológica). ¿En qué medida puedo considerarme nativo y en qué medida soy experto cuando estudio las fiestas de mi ciudad, una manifestación de protesta, un concierto de rock, una unidad hospitalaria? No se trata ya, en los términos en que alguna vez se planteó, de la banal discusión entre etnógrafos de fuera y de dentro - de la posibilidad de que los nativos ejerzan como "antropólogos de sí mismos", o de las virtudes relativas a cada una de estas posiciones-. Ese planteamiento es equívoco porque sigue tomando las posiciones de insider/outsider como inamovibles y dadas, como si trazaran una frontera siempre bien delimitada y estable. El problema, al menos en la antropología urbana en contextos modernizados, es que esa línea es sutil y mudable. Las barreras entre dentro/fuera poseen múltiples niveles y se desplazan permanentemente. Uno puede ser "colega" para un grupo de rockeros, "técnico cultural" ante un organizador de fiestas, "padre" para una enfermera de neonatos ${ }^{2}$. O puede ser un completo extraño para todos ellos, con independencia de su origen, lengua y nacionalidad.

La confusión es de doble dirección. No es sólo que la identidad cultural del observador sea múltiple y contenga grados muy variables de distancia o familiaridad en relación con los objetos de estudio. Es que, a la inversa, la identidad social de los sujetos también está permeada de múltiples formas por la reflexividad institucional moderna. Haciendo trabajo de campo urbano

\footnotetext{
${ }^{2}$ Estos desplazamientos del rol del investigador resultan elocuentes en la etnografía que realicé recientemente en una unidad hospitalaria de cuidados intensivos con neonatos (Velasco et al. en preparación). Para las enfermeras y auxiliares nunca dejé de ser alguien del entorno de los médicos. Por su parte, éstos me categorizaron inicialmente como una especie de experto en análisis de organizaciones laborales (por tanto, un igual), si bien con el tiempo acabaron construyendo para mí una categoría ad hoc, "el de la tribu de las focas", humorística y por tanto segregada de cualquier sistema de expectativas ordinarias. Por otro lado, en una planta manejada fundamentalmente por médicas - mujeres y madres-, la condición de adulto sin hijos no resultaba irrelevante. Pues, según fui descubriendo, mi perfil social me hacía candidato a usuario del servicio.
} 
uno tiene informantes que son sociólogos, líderes de movimientos sociales y hasta teóricos de la globalización; encuentra nativos que leen a los antropólogos o que, más a menudo, actúan como ellos; recoge discursos informados por categorías fundamentalmente sociológicas, objetivantes; y tiene que entrar en competencia (a veces en inferioridad de condiciones) con toda una lista de otros mediadores culturales abocados, como él, a producir imágenes de conjunto de la situación.

El resultado es una descripción que podríamos denominar, siguiendo a los lingüistas, beteroglósica: marcada por la confusión entre lenguajes, la combinación de categorías de distinto nivel de abstracción, la circularidad explicativa y - lo que más nervioso pondría a un antropólogo social inglés - la falta de parsimonia. Para empezar, no existe el "extrañamiento" categorial de partida que inaugura la anécdota del embrollo en la etnografía clásica. En nuestras ciudades, hoy, es difícil extrañarse de algo, asustarse de algo (aunque vivamos permanentemente asustados). La entrada en representación de algo que merece ser etnografiado - es decir, que merece una atención explicativa- sólo se consigue tras un arduo trabajo de explicitación y rodeos propedéuticos. Luego, el desarrollo etnográfico nunca conducirá a la traducción mutua de dos lenguajes cerrados en sí mismos, sino a un intercambio entre términos del vocabulario de la profesión y niveles dispares de pertenencia cultural, algunos de los cuales comparte el observador. El campo de las categorías nativas no es nunca uno: son muchos y borrosos, e incluyen parcialmente el suyo propio. El efecto epistemológico es oscilante. A veces se cae en la banalidad descriptiva, pues la etnografía de lo obvio siempre roza el límite inferior de la trivialidad, sin arrojar apenas otra información que la previsible desde el sentido común. A veces, por el contrario, se rebasa el límite superior de la sobreinterpretación hasta llegar al despropósito. En todo caso, siempre amenaza una circularidad explicativa donde categorías nativas y terminología profesional se remiten mutuamente.

Pese a tales limitaciones, las virtudes de una etnografía en casa no han sido suficientemente destacadas. En primer lugar, su potencial de extrañamiento, su capacidad de producir insights valiosos por el mero expediente de yuxtaponer categorizaciones incongruentes, mostrando las anomalías internas del sistema, las zonas ocultadas de nuestra realidad cotidiana y sus contradicciones. Mientras el trabajo en sociedades "exóticas" es típicamente coherencialista, la etnografía en casa tiene el carácter de un dispositivo irónico.

En segundo lugar, esta forma de etnografía posee una innegable veracidad frente a cualquier impostura etnográfica: no se presta fácilmente a la suplantación del sujeto etnografiado por la voz monológica del etnógrafo. La facilidad con que se ejerce la ventriloquía a kilómetros de distancia y para públicos aislados del campo de obtención de los datos está ausente allí don- 
de al juego circular de las categorías corresponde una circulación real, efectiva, de los puntos de vista.

En tercer lugar, el discurso científico se vincula éticamente con procesos sociales concretos. Al convertirse la monografía en parte del circuito comunicativo donde los datos están integrados, el antropólogo no puede escapar $\tan$ alegremente a las consecuencias de lo que dice. La dialogicidad no es aquí metáfora bienpensante, sino hecho fáctico —e inevitable- que enfrenta al antropólogo con las consecuencias extracientíficas de su trabajo. Buen ejemplo de esto lo representa la polémica entre Zulaika y Aranzadi en la revista Antropología sobre las relaciones entre ETA y la cultura vasca (Zulaika 1993, 1994; Aranzadi 1993). La imposibilidad de que una etnografía de la violencia cercana deje al margen las actitudes y puntos de vista de los productores y receptores de la investigación nos lleva a pensar en tantos debates académicos que carecen por completo de ese sentido dramático de estar hablando de algo que importa.

Finalmente, este tipo de etnografía impulsa el reconocimiento de la diferencia intracultural, a menudo pasada por alto en nuestra vida cotidiana. El ejercicio de simplificación de las imágenes del Otro -buen salvaje o sanguinario cortador de cabezas - se hace aquí más limitado. Las fronteras de la alteridad no están dadas de antemano, como un a priori que segrega al investigador de su objeto. Aparecen como posicionales y móviles, en función de múltiples criterios susceptibles de ser propugnados o impugnados por los actores. El mismo ejercicio de trazar mapas y líneas divisorias sobre la diversidad de la propia cultura es ya un desafío para la investigación. El resultado es un plus de reflexividad etnográfica, en el sentido de que es difícil que el investigador quede intocado en sus representaciones del objeto, porque es tanto observador como materia de la observación. Al tornar explícitos los vínculos que organizan en un todo las partes heterogéneas del agregado social, la etnografía pluraliza el entorno propio, hace emerger la alteridad invisible contenida en el medio al que uno pertenece.

En resumen, debido a que no permite una separación clara entre observador y observado, entre teoría reconstructiva y teoría empírica, entre lenguaje analítico y lenguaje objeto, la antropología en casa es etnográficamente impura y analíticamente poco parsimoniosa. A veces nos deja con la sensación de que para ese viaje no se necesitaban alforjas, dado que su destino es volver al punto del que partió. Pero es un fracaso del que podemos sacar provecho crítico, porque hace aparecer nuestro propio arbitrario como un mundo posible, una construcción cultural entre otras. De ahí la sensación de irrealidad que suscita el planteamiento etnográfico en los contextos globalizados y urbanos. "¿Qué vienes a hacer aquî?", me preguntó una vez un informante reticente, "me parecería más interesante que estudiaras a los salvajes de Papúa". 


\title{
CONCLUSIÓN. LAS RECOMPENSAS DE LA ETNOGRAFÍA
}

\begin{abstract}
Comencemos con una suave provocación: creemos que la teoría antropológica es una contradicción en términos. Considérese el tropo de moda de que la antropología produce conocimiento dialógico. La teoría antropológica sería como una teoría de la conversación, como si uno no pudiera implicarse en una conversación más que si tuviera una teoría de la conversación. Tal teoría convertiría el conocimiento dialógico en un monólogo (Editorial, EASA Newsletter 2000: 2. La traducción es mía).
\end{abstract}

En una época de crisis teórica de la antropología, la etnografía es y continuará siendo, a mi juicio, su aportación más viva al desarrollo del diálogo en las ciencias sociales. Precisamente en las dificultades aquí reseñadas, en su apertura a contextos mal definidos, su permeabilidad a las lógicas dispares de los agentes, el carácter posicional y situado del conocimiento que produce, su falta de cierre categorial, es donde residen sus mayores virtudes como método para entender las imbricaciones, los cruces y los mestizajes en la cultura contemporánea. Esas dificultades de la etnografía son una especie de alegoría tardomoderna del diálogo como aspecto esencial de la condición humana —el diálogo, entendido a la manera bajtiniana, como "la unidad simultánea de las diferencias en el acto de la enunciación" (Holquist 1990: 36)—. Estas dificultades para el mapeo totalizador, para la traducción entre inconmensurables, no sólo reflejan las propias de todo diálogo como algo por definición abierto, inconcluso. Resumen también las de una época. Por ellas entendemos mejor los tanteos a ciegas de nuestros informantes en su pugna por dotar de sentido a sus prácticas locales, por evitar su vaciamiento o por conseguir definir su lugar en el mundo. $\mathrm{Y}$ hasta los de las mismas ciencias sociales, en su esfuerzo por construir discursos sobre el hombre.

Para mí, personalmente, el método etnográfico supone el momento de una restitución, donde la práctica de la antropología recobra su sentido. Pues en la práctica etnográfica experimentamos el hecho de que, aunque no tengamos una teoría del diálogo, la antropología efectivamente sirve para dialogar. La etnografía es, en esa medida, uno de los métodos de las ciencias sociales más frágiles y difíciles, siempre susceptible de apropiaciones perversas, de ejercicios de impostura y ventriloquia. Pues siempre será posible amañar en forma de diálogo, mediante una hábil edición etnográfica, lo que no fue sino rapiña e invención ("De cosas mal dichas se escriben los libros", me espetó una vez un informante). Sin embargo, la etnografía es también un espacio de descubrimientos y autodescubrimientos, el encuentro fundamental con la materia básica de la que está hecha nuestra extraña ciencia. Estudiamos al otro en sus contradicciones para saber algo de nosotros mismos. 


\section{BIBLIOGRAFÍA CITADA}

ABU-LUGHOD, LILA. 1991. "Writing against culture", en R. G. Fox (ed.), Recapturing Anthropology. Santa Fe: School of American Research Press.

AGNEw, JOHN. 1998. Geopolitics. Re-visioning world politics. Londres y Nueva York: Routledge.

AppaDURAI, ARJun. 1986. "Introduction: Commodities and the politics of valuen, en A. Appadurai (ed.), The Social Life of Things. Cambridge: Cambridge University Press. ARANZADI, JUAN. 1993. "Sangre simbólica e impostura antropológica". Antropología 6: 65-96.

ASAD, TALAL. 1991. "El concepto de la traducción cultural en la antropología social británica”, en J. Clifford y G. Marcus (eds.), Retóricas de la antropología: 205-234. Barcelona: Júcar.

AugÉ, MARC. 1998. Los no lugares, espacios del anonimato. Una antropología de la sobremodernidad. Barcelona: Gedisa.

BAKHTIN, MiKHAIL M. 1981. "Forms of time and chronotope in the novel", en The Dialogic Imagination: 84-258. Austin: University of Texas Press.

BARley, Nigel. 1989. El antropólogo inocente. Notas desde una choza de barro. Barcelona: Anagrama.

BAUMAN, ZYGMUNT. 1992. Intimations of Postmodernity. Londres: Routledge.

BAUMANN, GERD. 1996. Contesting culture: discourses of identity in multi-ethnic London. Cambridge: Cambridge University Press.

BOHANNAN, LAURA. 1993 [1966]. "Shakespeare en la selva", en H. Velasco (comp.), La cultura y las culturas. Lecturas de antropología social y cultural: 83-93. Madrid: UNED.

Clifford, JAmes y GeOrge E. Marcus (eds.). 1991. Retóricas de la antropología. Barcelona: Júcar.

CRUCES, FRANCISCO. 1994. "Los límites de la traducibilidad. Variaciones sobre un tema de Laura Bohannan", en A. Rosa y J. Valsiner (eds.), Explorations in Socio-Cultural Studies. Historical and Theoretical Discourse: 39-47. Madrid: Infancia y Aprendizaje.

- 1997. "Desbordamientos. Cronotopías en la localidad tardomoderna". Política y Sociedad 25: 45-58.

"Editorial. Anthropology and new age missionaries". 2000. EASA Newsletter 28: 2.

EVANS-PRITCHARD, EDWARD E. 1977 [1940]. Los Nuer. Barcelona: Anagrama.

FABIAN, JOHANNES. 1983. Time and the others: how antbropology makes its object. Nueva York: Columbia University Press.

GARCÍA CANClini, NÉSTOR. 1999. La globalización imaginada. Buenos Aires: Paidós.

-; Alejandro Castellanos y Ana Rosas MANTECón. 1996. La ciudad de los viajeros. Travesías e imaginarios urbanos: México 1940-2000. México: Grijalbo.

GEERTZ, ClifFORD. 1987 [1973]. La interpretación de las culturas. Barcelona: Gedisa.

GIDDENS, ANTHONY. 1994. Consecuencias de la modernidad. Madrid: Alianza.

GOODY, JACK. 1992. "Culture and its boundaries: a European view". Social Anthropology 1: 9-32.

GuADERRAMA, MARITZA. 1999. Espacialización social y prensa. Las representaciones del espacio en las noticias sobre América Latina en los diarios españoles. Tesis doctoral. Madrid: Universidad Complutense.

HANNERZ, UlF. 1998. Conexiones transnacionales. Cultura, gente, lugares. Valencia: Cátedra. 
HASTRUP, KIRSTEN. 1994. "Anthropological knowledge incorporated: discussion", en K. Hastrup y P. Hervik (eds.), Social Experience and Anthropological Knowledge: 224237. Londres: Routledge.

Holquist, Michael. 1990. Dialogism. Bakbtin and bis world. Londres: Routledge.

LEACH, EDMUND. 1971. Replanteamiento de la antropología. Barcelona: Seix Barral.

MaLINOWSKI, Bronislaw. 1992 [1922]. Los argonautas del Pacífico occidental. Barcelona: Península.

-. 1993. "Introducción. Cuestiones de método", en H. Velasco (comp.), La cultura y las culturas. Lecturas de antropología social y cultural: 131-153. Madrid: UNED.

MARCUS, GeOrGE E. 1995. "Ethnography in/of the World System: The Emergence of MultiSited Ethnography". Annual Review of Anthropology 24: 95-117.

MARTín-BARBERO, JeSús. 1987. De los medios a las mediaciones. Comunicación, cultura $y$ hegemonía. Barcelona: Gustavo Gili.

MUNN, NANCY. 1992. "The cultural anthropology of time. A critical essay". Annual Review of Anthropology 21: 93-123.

PeACOCK, JAMES L. 1993. "Método", en H. Velasco (comp.), La cultura y las culturas. Lecturas de antropología social y cultural: 155-198. Madrid: UNED.

REDFIELD, ROBERT. 1960. The little community and peasant society and culture. Chicago: The University of Chicago Press.

TAMBIAH, STANLEY J. 1990. Magic, science, religion and the scope of rationality. Cambridge: Cambridge University Press.

TURNER, STEPHEN. 1984. La explicación sociológica como traducción. México: FCE.

VELASCO, HONORIO et al. (en preparación). La sonrisa de la institución. Etnografía de confianza y riesgo en cinco sistemas expertos. Madrid: Trotta.

- y ÁNGel Díaz DE RADA. 1999. La lógica de la investigación etnográfica. Un modelo de trabajo para etnógrafos de la escuela. Madrid: Trotta.

Wallace, ANTHONY F. C. (1972) [1961]. Cultura y personalidad. Buenos Aires: Paidós. Zulaika, JosebA. 1993. "Violencia, Texto y Parodia". Antropología 6: 37-64.

-. 1994. "El antropólogo como impostor”. Antropología 7: 115-130. 